\title{
Neuroprotective effect of cellular prion protein (PrPC) is related with activation of alpha7 nicotinic acetylcholine receptor (a7nAchR)-mediated autophagy flux
}

\author{
Jae-Kyo Jeong ${ }^{1,2}$ and Sang-Youel Park ${ }^{1,2}$ \\ ${ }^{1}$ Biosafety Research Institute, College of Veterinary Medicine, Chonbuk National University, Jeonju, Korea \\ ${ }^{2}$ Department of Bioactive Material Sciences and Research Center of Bioactive Materials, Chonbuk National University, Jeonju, \\ Korea \\ Correspondence to: Sang-Youel Park, email: sypark@chonbuk.ac.kr \\ Keywords: autophagy flux, alpha-7 nicotinic receptor, prpc, prion, Geotarget \\ Received: April 03, $2015 \quad$ Accepted: June 28, 2015 \\ Published: July 22, 2015
}

This is an open-access article distributed under the terms of the Creative Commons Attribution License, which permits unrestricted use, distribution, and reproduction in any medium, provided the original author and source are credited.

\section{ABSTRACT}

Activation of the alpha7 nicotinic acetylcholine receptor ( $\mathrm{a} 7 \mathrm{nAchR})$ is regulated by prion protein (PrPC) expression and has a neuroprotective effect by modulating autophagic flux. In this study, we hypothesized that PrPC may regulate a7nAchR activation and that may prevent prion-related neurodegenerative diseases by regulating autophagic flux. $\operatorname{PrP}(106-126)$ treatment decreased a7nAchR expression and activation of autophagic flux. In addition, the $\mathbf{a 7 n A c h R}$ activator PNU-282987 enhanced autophagic flux and protected neuron cells against $\operatorname{PrP}(106-126)$-induced apoptosis. However, activation of autophagy and the protective effects of PNU-282987 were inhibited in PrPC knockout hippocampal neuron cells. In addition, PrPC knockout hippocampal neuron cells showed decreased a7nAchR expression levels. Adenoviral overexpression of PrPC in PrPC knockout hippocampal neuron cells resulted in activation of autophagic flux and inhibition of prion peptide-mediated cell death via a7nAchR activation. This is the first report demonstrating that activation of a7nAchRmediated autophagic flux is regulated by PrPC, and that activation of a7nAchR regulated by PrPC expression may play a pivotal role in protection of neuron cells against prion peptide-induced neuron cell death by autophagy. These results suggest that a7nAchR-mediated autophagic flux may be involved in the pathogenesis of prionrelated diseases and may be a therapeutic target for prion-related neurodegenerative diseases.

\section{INTRODUCTION}

Alpha-7 nicotinic acetylcholine receptors $(\alpha 7 \mathrm{nAchR})$, also known as $\alpha 7$ nicotinic receptors, are a family of nicotinic acetylcholine receptors that regulate long-term memory and consist entirely of $\alpha 7$ subunits [1-3]. This receptor is distributed in the brain, endothelium, muscle and lymphocytes [2, 4-6]. $\alpha 7 \mathrm{nAchR}$ are activated by post- and pre-synaptic excitation, mainly by increased calcium permeability [7,8]. Recent work suggests that activation of these receptors is regulated by stress-inducible protein 1 through cellular prion protein (PrPC) signals [9]. In addition, activation of $\alpha 7 \mathrm{nAchR}$ has a neuroprotective effect against misfolded protein-mediated neurodegenerative diseases, including
Alzheimer's, and Parkinson's diseases [10-13]. Hung et al. found that autophagy-mediated amyloid beta $(A \beta)$ clearance is regulated by activation of $\alpha 7 \mathrm{nAchR}$ in $\mathrm{SH}-$ SY5Y neuroblastoma cells [13]. Another study showed that some $\alpha 7 n A c h R$ agonists (AQW051 and PNU-282987) protects the brain from 1-methyl-4-phenyl-1,2,3,6tetrahydropyridine (MPTP)-induced parkinsonism [10, 14]. In addition, $\alpha 7 \mathrm{nAChR}$ antagonist, methyllycaconitine blocked the nicotine-mediated neuroprotective effect in differentiated PC-12 cells [15]. These data suggest that activation of $\alpha 7 \mathrm{nAchR}$ is regulated by $\mathrm{PrPC}$ expression and may have a neuroprotective effect against neurodegenerative disorders by interacting with PrPC signals.

PrPC is normal prion protein distributed in various 
tissues, including the lung, intestinal tract, and brain and is a glycosylated-phosphatidylinositol-anchored membrane protein involved with regulating neurosignals [16-20]. One study showed that PrPC may influence autophagic flux, although the molecular mechanisms are unclear [21]. Oh et al. suggested that PrPC protects hippocampal neuron cells against autophagic cell death caused by serum deprivation in $\operatorname{PrnP}^{-/-}$hippocampal neuron cells [21]. Additionally, knockdown of PrPC expression in various cancer cells increases autophagy-mediated cell death [22]. However, one study suggested that PrPC has a neuroprotective effect associated with induction of autophagy against oxidative stress in hippocampal neuron cells [23]. Moreover, Shin et al. found that the increase of autophagic flux caused by depletion of PrPC is correlated with age in the hippocampus compared to that in normal mice [24]. The same study suggested that a PrPC deficiency may disrupt autophagic flux by blocking autophagosome-lysosomal fusion [24]. These results suggest that $\mathrm{PrPC}$ is a key factor in the regulation of autophagic flux in the brain, although the relationship between PrPC and autophagic flux is unclear.

Autophagy is well known process for degrading cytoplasmic components via the lysosomal pathway [25-28]. During autophagy, LC3-I (cytosolic form) is conjugated to $\mathrm{PE}$ (phosphatidylethanolamine) and form LC3-II (LC3-PE conjugated form) [29, 30]. It is composited to autophagosomal membranes, and which is degraded by lysosomal digestion after the fusion of Avs (autophagic vacuoles) with lysosomes [31, 32]. Thus, increase of LC3-II indicated that activating autophagy. But some paper showed that inhibition of autophagy also increased LC3-II form [33]. A block of lysosomal fusion with AVs inhibited degradation of LC3-II forms [33]. Also, autophagic flux is inhibited, the level of p62, an ubiquitin- and LC3-binding protein, is accumulated $[34,35]$. Thus, the comparative analysis about the LC3II/LC3-I ratio and p62 accumulation for the detection of autophagic flux is necessary. And, some paper showed that accumulation of p62 is detected in neurodegenerative disorders including Parkinson disease, Alzheimer disease and Huntingtin aggregates in Huntington disease [36-38]. In addition, some studies have suggested that activating this process plays a pivotal role in various conditions, including adaptation to starvation and anti-cancer and neuroprotective effects [39-44]. It is well known that starvation stimulates the sirtuin family of deacetylases, thereby activating autophagic flux [45-47]. In addition, activation of autophagic flux increases $A \beta$ clearance and protects neuronal cells against $A \beta$-mediated neurotoxicity by activating $\alpha 7 \mathrm{nAchR}$ in SH-SY5Y neuroblastoma cells [13]. However, a defect in $\alpha 7 \mathrm{nAchR}$ signaling may impair autophagic flux, thereby suppressing clearance of $A \beta$, leading to increased neurotoxicity [13]. These results suggest that the regulation of autophagic flux is a key mechanism for preventing neural dysfunction. In particular, activating autophagic flux through $\alpha 7 \mathrm{nAchR}$ signaling may prevent misfolded protein-mediated neurodegenerative disorders including Alzheimer's, Parkinson's, and prion diseases. Our previous study showed that overexpressing PrPC [48] and activating autophagy protects neuron cells against $\operatorname{PrP}(106-126)-$ mediated neurotoxicity [43, 44], respectively. However, the relationship between PrPC and autophagy and prion peptide-mediated neurotoxicity has not been reported.

Thus, the present study focused on the relationship between PrPC expression and the regulation of autophagic flux during $\operatorname{PrP}(106-126)-$ mediated neurotoxicity and estimated the influence of $\alpha 7 \mathrm{nAchR}$ signaling. The results show that activating $\alpha 7 \mathrm{nAchR}$ upregulates autophagic flux and protects hippocampal neuron cells against $\operatorname{PrP}(106-$ 126)-mediated neurotoxicity. However, the protective effect and upregulation of autophagic flux caused by activating $\alpha 7 \mathrm{nAchR}$ was suppressed by decreasing PrPC gene expression. These results suggest that $\alpha 7 \mathrm{nAchR}$ mediated autophagic flux may be regulated via PrPC expression and that regulating PrPC expression is applicable as a therapeutic strategy for neurodegenerative disorders including prion disease.

\section{RESULTS}

\section{Regulation of $\alpha 7 n$ AchR activity influences PrP(106-126)-mediated neurotoxicity by upregulating autophagic flux in primary neuron cells}

Our previous study suggested that activating autophagy protects neuronal cells against $\operatorname{PrP}(106-126)-$ mediated neurotoxicity [43, 44]. Another study showed that activating $\alpha 7 \mathrm{nAchR}$ upregulates autophagic flux and protects SH-SY5Y cells against A $\beta$-induced neurotoxicity [13]. However, the influence of $\alpha 7 \mathrm{nAChR}$ in prionmediated neurotoxicity has not been reported. Thus, we determined whether activating $\alpha 7 \mathrm{nAChR}$ upregulates autophagic signaling during $\operatorname{PrP}$ (106-126)-induced apoptosis (Figure 1). Primary cultured neuronal cells were exposed to the $\alpha 7 \mathrm{nAChR}$ inhibitor MLA or the $\alpha 7 \mathrm{nAChR}$ activator PNU-282987 for $12 \mathrm{hr}$ and were treated with 50 $\mu \mathrm{M}$ PrP (106-126) for $24 \mathrm{hr}$. The Annexin V assay results show that the number of apoptotic cells decreased after PNU-282987 treatment in the $\operatorname{PrP}(106-126)$-treated groups (Figure 1A and 1B). Additionally, the number of Annexin $\mathrm{V}$-positive cells increased following MLA treatment in PrP (106-126)-treated cells (Figure 1A and 1B). These data show that activating $\alpha 7 \mathrm{nAChR}$ signaling protects neuron cells against prion-mediated neurotoxicity.

One study suggested that activating $\alpha 7 \mathrm{nAChR}$ may upregulate autophagic flux; thus, we determined whether activating $\alpha 7 \mathrm{nAChR}$ influenced autophagic flux 
in $\operatorname{PrP}(106-126)$-treated cells (Figure 1C). Cells were pretreated with MLA (50 nM, 12 hr) or PNU-282987 (1 $\mu \mathrm{M}$, $12 \mathrm{hr}$ ) and were then exposed to $50 \mu \mathrm{M} \operatorname{PrP}(106-126)$ for $12 \mathrm{~h}$. that the results show that protein levels of $\alpha 7 \mathrm{nAChR}$ decreased and those of LC3-II/LC3-I ratio and p62 increased (autophagic flux inhibition marker) following PrP (106-126) treatment. Additionally, MLA reinforced the inhibition of autophagic signals caused by $\operatorname{PrP}(106-$ 126) treatment. However, PNU-282987 increased LC3-II/ LC3-I ratio and decreased p62 protein levels, indication of activating autopagic flux, in the $\operatorname{PrP}(106-126)$-treated group, but $\alpha 7 \mathrm{nAChR}$ expression did not change (Figure $1 C)$. These results suggest that activating $\alpha 7 \mathrm{nAChR}$ signaling protects neuron cells against $\operatorname{PrP}(106-126)-$ mediated apoptosis by upregulating autophagic flux.

To verify that $\alpha 7 \mathrm{nAChR}$ plays a protective role in $\operatorname{PrP}(106-126)$-treated neuron cells via activation of autophagic flux, we suppressed $\alpha 7 \mathrm{nAChR}$ gene expression using an $\alpha 7 \mathrm{nAChR}$ RNAi oligomer in primary neuron cells treated with $\operatorname{PrP}(106-126)$ and PNU-282987 as a $\alpha 7 \mathrm{nAChR}$ activator. The number of Annexin V-positive cells no changed in $\alpha 7 \mathrm{nAChR}$ RNAi oligomer $(\alpha 7 \mathrm{nAChR}$
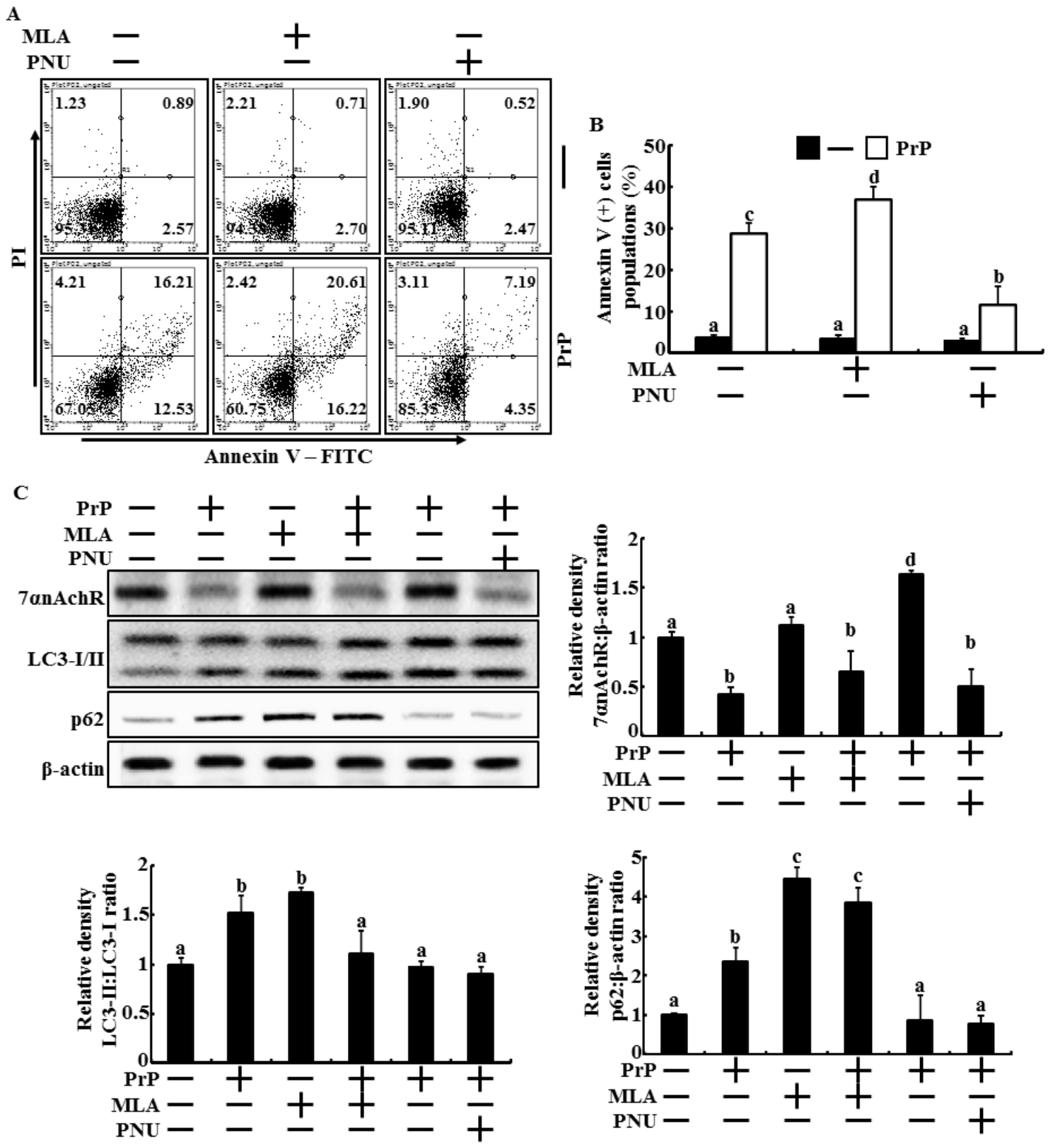

Figure 1: Regulation of $\alpha$ 7nAchR activity influenced to autophagic flux and prevents primary neuron cells from PrP(106126) treatment. A. Primary neuron cells were treated with PNU-282987 (1 $\mu \mathrm{M}, 12 \mathrm{hr}$ ) or MLA (50nM, 12hr) and then exposed to 50 $\mu \mathrm{M}$ of $\operatorname{PrP}(106-126)$ for $24 \mathrm{~h}$. Cell viability was measured by the Annexin V assay. B., Bar graph indicated that the averages of annexin V positive cells. C., Western blot assay in primary neuron cells treated as described in A. The treated cells were assessed for LC3-1/II, p62 and $\alpha 7 \mathrm{nAchR}$ production by Western blot analysis. Results were normalized with $\beta$-actin. Expression levels were determined by western blot band quantifications and densitometric values are shown beside the blot. 
siRNA, si- $\alpha 7 \mathrm{nAChR})$ transfected cells. However, treatment of $\operatorname{PrP}(106-126)$ increased apoptotic cells populations in si- $\alpha 7 \mathrm{nAChR}$ transfected cells compared to negative control RNAi oligomer (si-NC) transfected cells (Figure 2A). In addition, the protective effect of PNU282987 against $\operatorname{PrP}(106-126)$-mediated neurotoxicity inhibited by knockdown of $\alpha 7 \mathrm{nAChR}$ in primary neuronal cells (Figure 2A). Additionally, Western blot analysis showed that the treatment of si- $\alpha 7 \mathrm{nAChR}$ inhibited $\alpha 7 \mathrm{nAChR}$ protein levels and increased LC3-II/LC3-I ratio and p62 protein levels compared to those in negative control RNAi oligomer (si-NC)-treated cells (Figure 2B). Also, treatment of si- $\alpha 7 \mathrm{nAChR}$ increased the inhibition of autophagic flux in $\operatorname{PrP}(106-126)$-treated cells (Figure 2B). Collectively, these data suggest that regulation of $\alpha 7 \mathrm{nAChR}$ signaling influenced to prion-mediated neurotoxicity via modulation of autohpagic flux pathway.
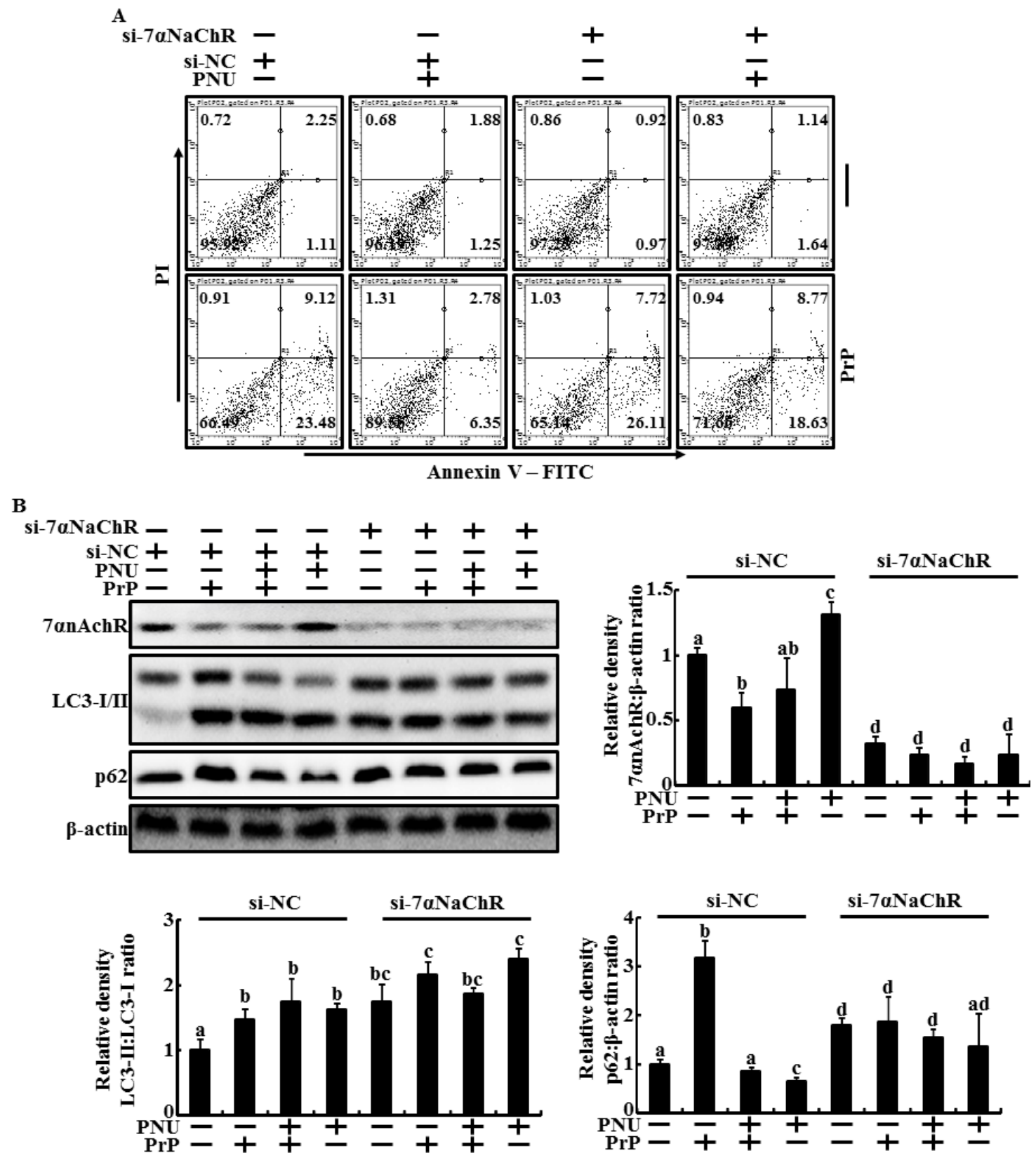

Figure 2: Knockdown of $\alpha 7 n$ AchR inhibited the PNU-282987-mediated neuroprotective effect and autophagic flux in primary neuron cells. A., $\alpha 7 \mathrm{nAchR}$ siRNA (si- $\alpha 7 \mathrm{nAChR}$ ) or Negative control siRNA (NC) transfected primary neuron cellsls were treated with PNU-282987 (1 $\mu \mathrm{M}, 12 \mathrm{hr})$ and then exposed to $50 \mu \mathrm{M}$ of $\operatorname{PrP}(106-126)$ for $24 \mathrm{~h}$. Cell viability was measured by the Annexin V assay. B., Western blot assay in primary neuron cells treated as described in A. The treated cells were assessed for LC3-I/II, p62, PrPC and $\alpha 7 \mathrm{nAchR}$ production by Western blot analysis. Results were normalized with $\beta$-actin. Expression levels were determined by western blot band quantifications and densitometric values are shown beside the blot. The bar graph indicates the mean \pm S.E.M. $(n=3)$. 


\section{Depleting PrPC and $\operatorname{PrP(106-126)}$ inhibits $\alpha 7 n A C h R$ expression and autophagic flux in hippocampal neuron cells}

One study showed that depleting PrPC blocks activation of $\alpha 7 \mathrm{nAChR}$ signaling and inhibits autophagic flux signals. However, the relationship between autophagy and $\mathrm{PrPC} / \alpha 7 \mathrm{nAChR}$ signals in prion-mediated neurotoxicity is unknown. Thus, we investigated whether PrPC expression influences $\alpha 7 \mathrm{nAChR}$-mediated autophagic flux signaling in $\operatorname{PrP}(106-126)$-treated neuronal cells. We cultured the mouse hippocampal neuron cell lines ZW 13-2 and Zpl 3-4, which were established from the hippocampus of ICR $\left(\right.$ Prnp $\left.^{+/+}\right)$and Zürich I Prnp ${ }^{-/}$ mice, respectively. Western blot assays showed that PrP(106-126) treatment decreased LC3-II/LC3-I ratio and $\alpha 7 \mathrm{nAChR}$ protein levels increased p62 protein levels in ZW 13-2 cells. In addition, P62 protein levels increased in PrPC-knockout Zpl 3-4 cells compared to those in ZW 13-2 cells. Zpl 3-4 cells decreased the $\alpha 7 \mathrm{nAChR}$ protein levels compared to ZW-13-2 cells (Figure 3A and 3B). Consistent with these results, fluorescence microscopy showed that PrP(106-126) treatment or depleting PrPC expression resulted in low fluorescence (Figure 3C). These data indicate that PrPC expression plays a main role in $\alpha 7 n A C h R-m e d i a t e d$ autophagic flux in $\operatorname{PrP}(106-126)-$ treated hippocampal neuron cells.
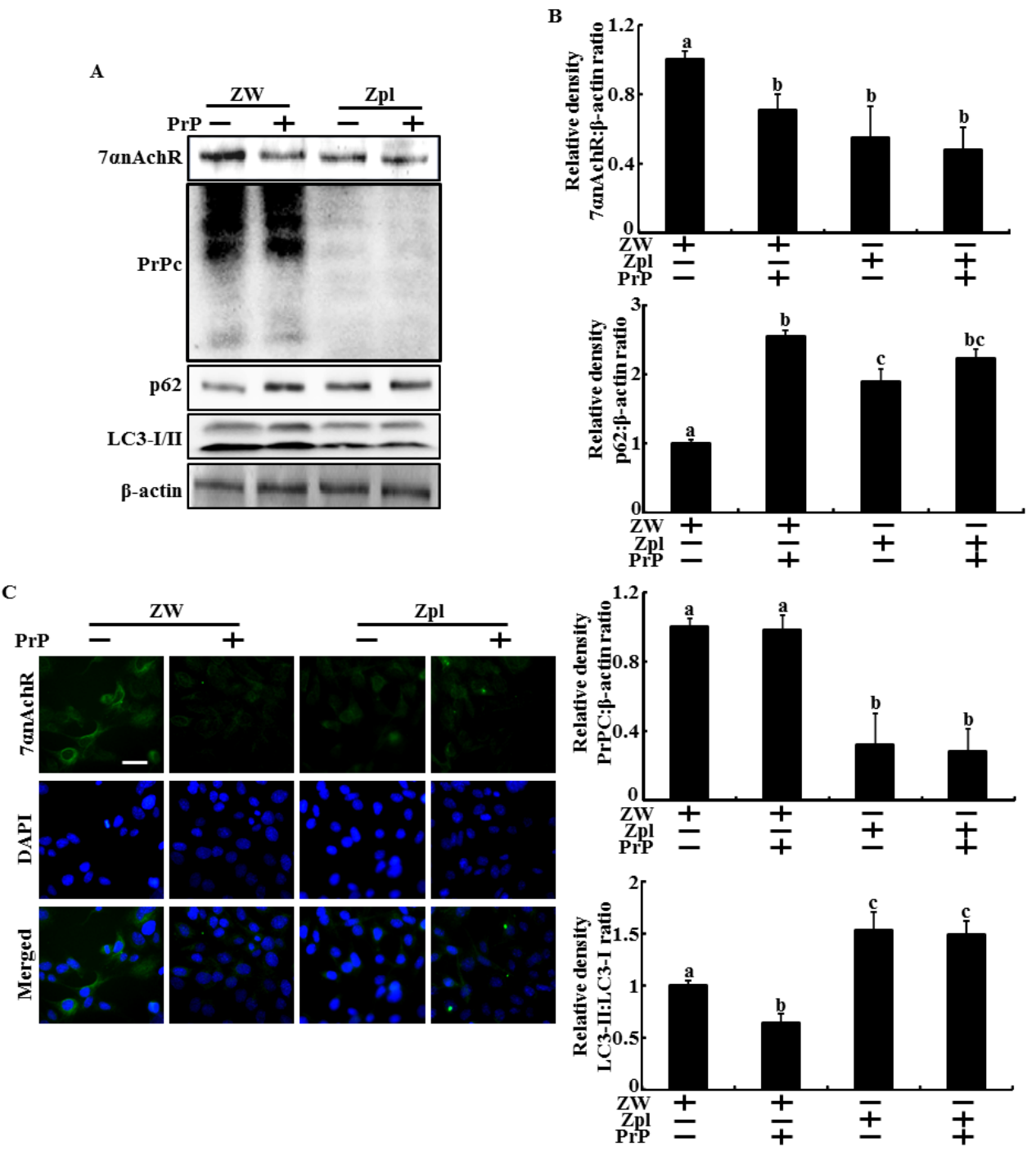

Figure 3: Depletion of PrPC and $\operatorname{PrP}(106-126)$ inhibited the alpha $7 \mathrm{nAchR}$ expression and autophagic flux in

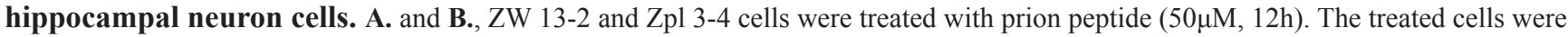
assessed for LC3-I/II, p62, PrPC and $\alpha 7 n$ AchR production by Western blot analysis. Results were normalized with $\beta$-actin. Expression levels were determined by western blot band quantifications and densitometric values are shown beside the blot. The bar graph indicates the mean \pm S.E.M. $(n=3)$. C., Representative images of Immunocytochemistry in ZW 13-2 and Zpl 3-4 cells treated as described in A. The treated cells were immunostained with DAPI (blue) and $\alpha 7 n A c h R$ antibody (green) and fluorescence was examined. Magnification $400 \times$, scale bar $=20 \mu \mathrm{m}$ 
PrPC depletion influences $\alpha 7 n A C h R$-mediated autophagic flux signaling in $\operatorname{PrP}(106-126)$-treated hippocampal neuron cells
To verify that $\alpha 7 \mathrm{nAChR}$ plays a protective role in PrP(106-126)-treated neuron cells via PrPC expression and to determine whether the neuroprotective effect of $\alpha 7 \mathrm{nAChR} / \mathrm{PrPC}$ signaling is related with autophagic flux,

$\mathbf{A}$

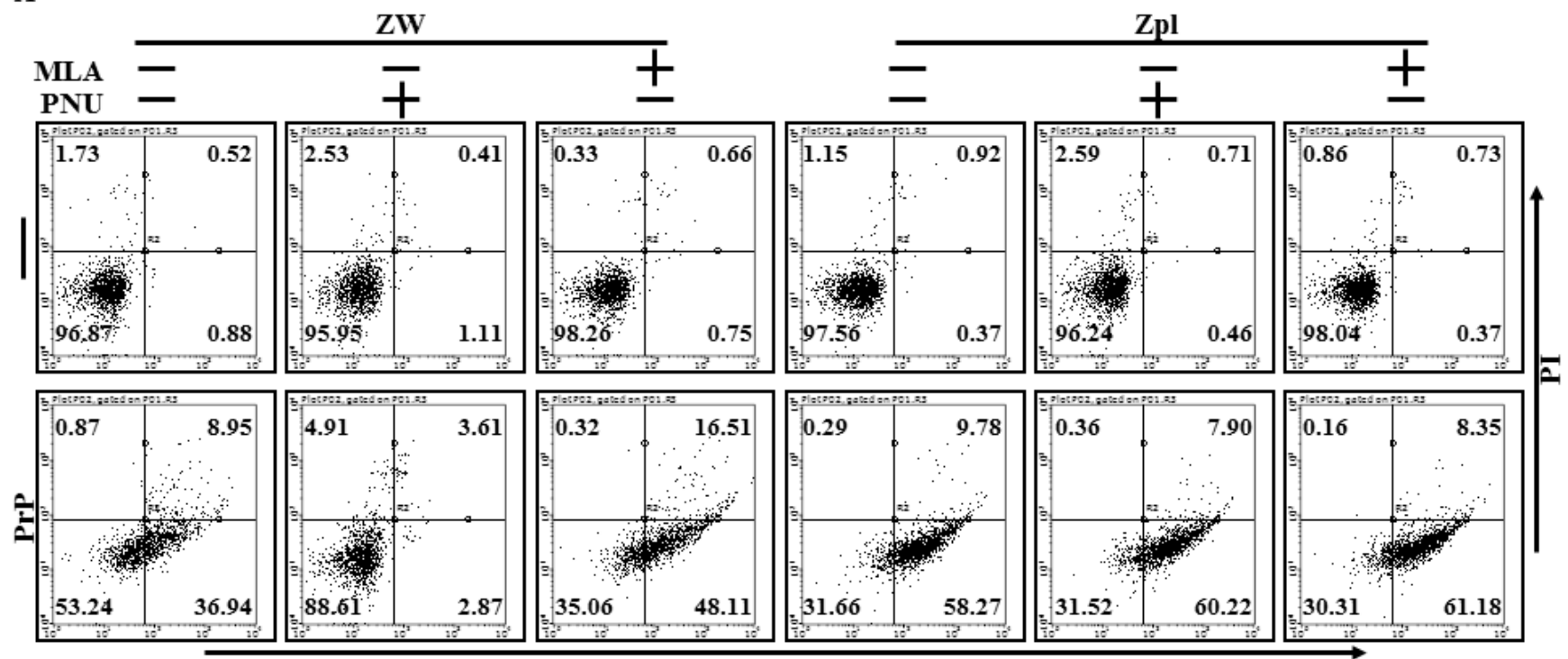

Annexin V-FITC
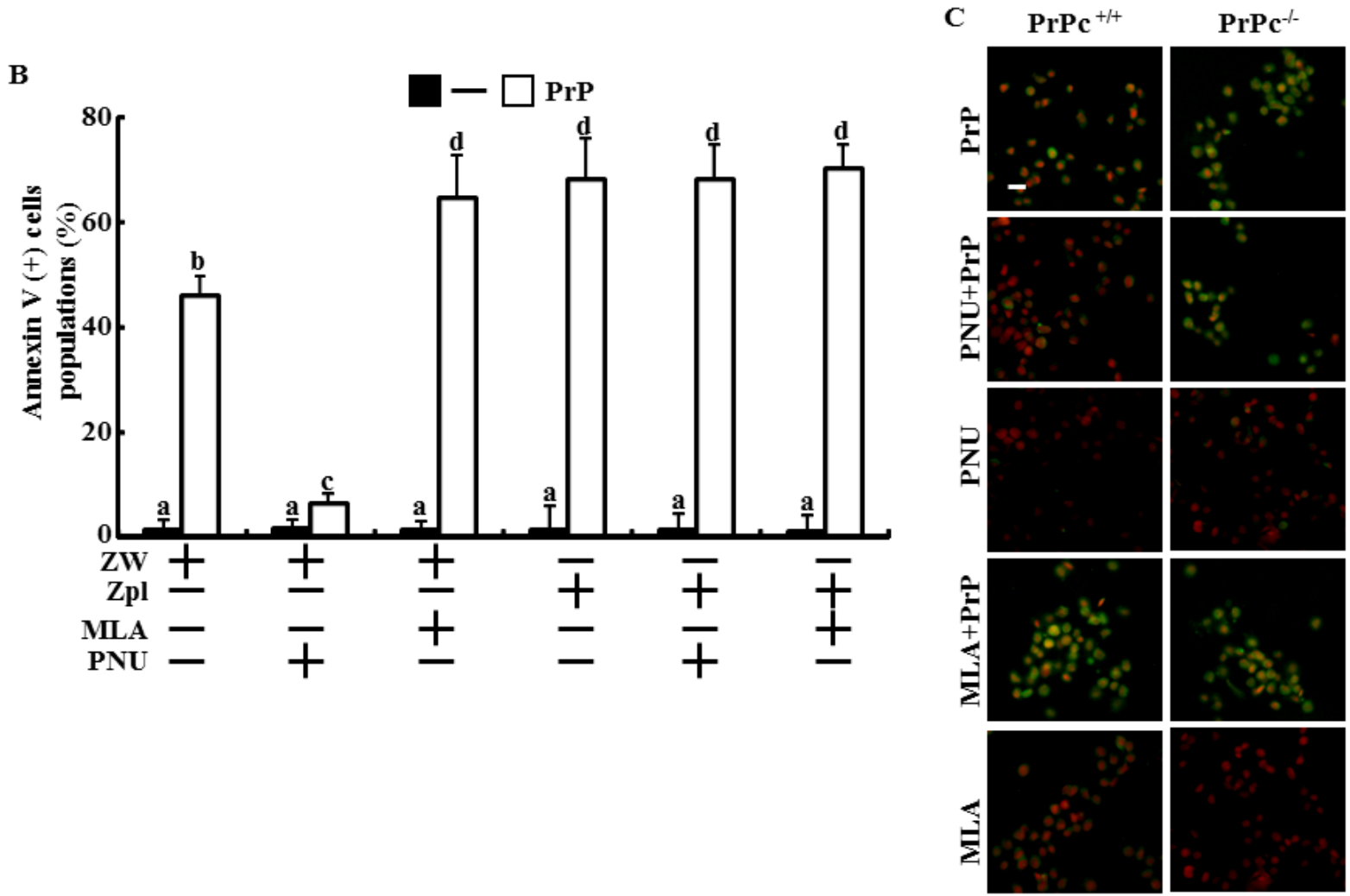

Figure 4: Regulation of alpha $7 \mathrm{nAchR}$ activity influenced to the protective effect of PrPC against PrP(106-126)mediated neurotoxicity. A., ZW 13-2 and Zpl 3-4 cells were treated with PNU-282987 (1 $\mu$ M, $12 \mathrm{hr})$ or MLA (50nM, 12hr) and then exposed to $50 \mu \mathrm{M}$ of $\operatorname{PrP}(106-126)$ for $24 \mathrm{~h}$. Cell viability was measured by the Annexin V assay. B., Bar graph indicated that the averages of annexin V positive cells. C., Representative immunofluorescence images of TUNEL-positive (green) ZW 13-2 and Zpl 3-4 cells pretreated with PNU-282987 (1 $\mu \mathrm{M}, 12 \mathrm{hr})$ or MLA (50nM, 12hr) and then exposed to PrP(106-126). The cells were counterstained with propidium iodide (red) to show all cell nuclei. Magnification $400 \times$, scale bar $=20 \mu \mathrm{m}$. 
cell viability and the signaling pathways were evaluated in ZW 13-2 and Zpl 3-4 cells treated with PrP(106-126) and either PNU-282987 as a $\alpha 7 \mathrm{nAChR}$ activator or MLA as a $\alpha 7 \mathrm{nAChR}$ suppressor. The number of Annexin V-positive cells increased in Zpl 3-4 cells compared to that in ZW 13-2 cells after PrP(106-126) treatment (Figure 4A and 4B). Additionally, PNU-282987 protected ZW 13-2 cells against $\operatorname{PrP}(106-126)$-induced apoptosis but the protective effect of PNU-282987 was inhibited in Zpl 3-4 cells. MLA increased $\operatorname{PrP}(106-126)$-mediated neurotoxicity in ZW 13-2 cells, whereas it's effect was blocked in Zpl 3-4 cells (Figure 4A and 4B). These results were further confirmed by measuring TUNEL fluorescence (Figure 4C). A Western blot analysis showed that the PNU-282987 and PrP(106-
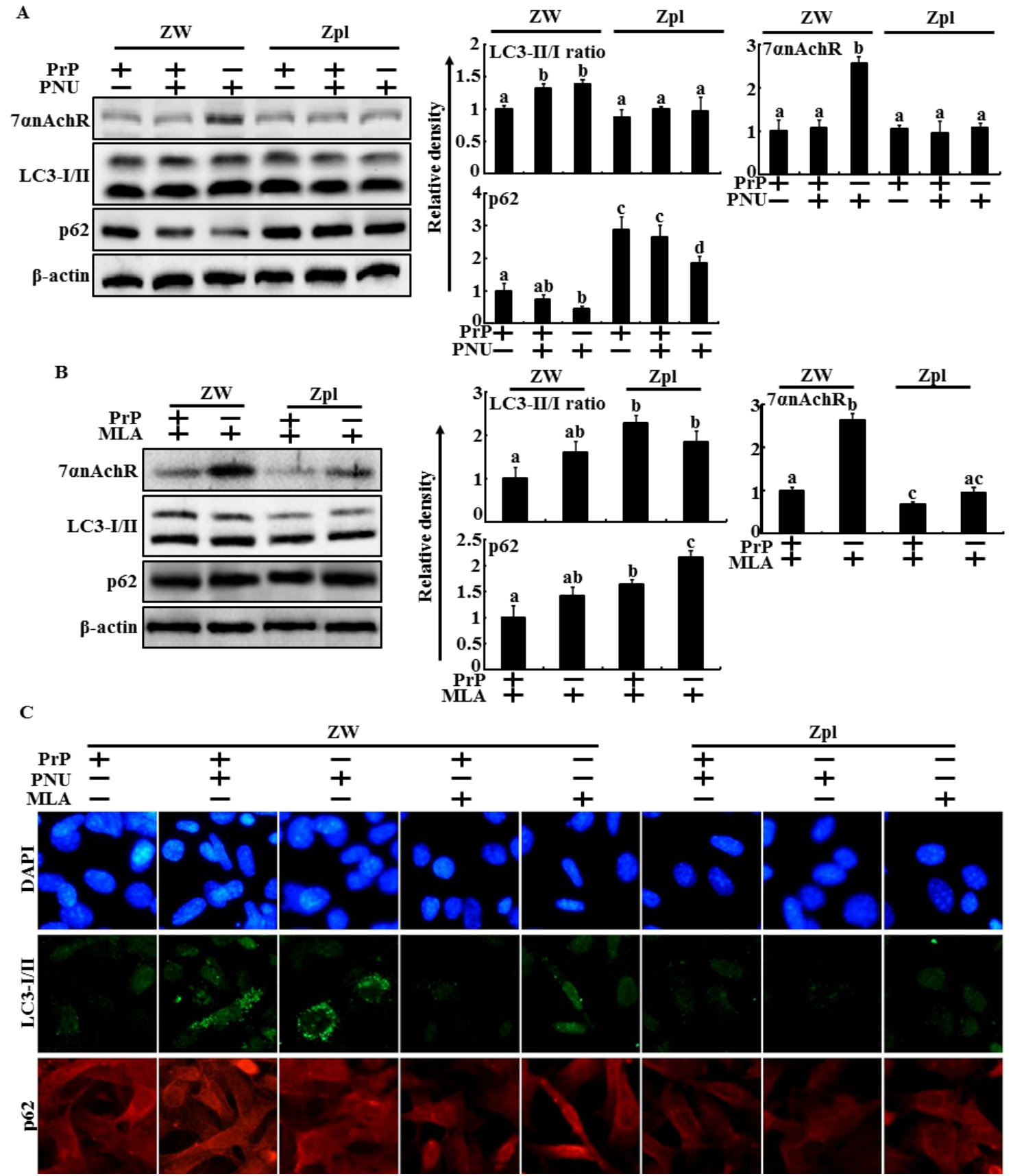

Figure 5: PrPC depletion influence to alpha 7 nAchR-mediated autophagic flux in PrP(106-126)-treated hippocampal neuron cells. A. and B., ZW 13-2 and Zpl 3-4 cells were treated with PNU-282987 (1 $\mu$ M, 12 hr) or MLA (50nM, 12hr) and then exposed to Prion peptide $(50 \mu \mathrm{M}, 12 \mathrm{~h})$. The treated cells were assessed for LC3-I/II, p62, PrPC and $\alpha 7 \mathrm{nAchR}$ production by Western blot analysis. Results were normalized with $\beta$-actin. Expression levels were determined by western blot band quantifications and densitometric values are shown beside the blot. C., Cells were treated with PNU-282987 (1 $\mu \mathrm{M}, 12 \mathrm{hr})$ or MLA (50nM, 12hr) and then exposed to Prion peptide $(50 \mu \mathrm{M}, 12 \mathrm{~h})$. The treated cells were immunostained with DAPI (blue) and $\alpha 7 \mathrm{nAchR}$ antibody (green) and fluorescence was examined. Magnification $400 \times$, scale bar $=20 \mu \mathrm{m}$. 
126) co-treated group had increased LC3-II/LC3-I ratio and decreased p62 protein levels compared to those in the PrP(106-126) only treated group of ZW 13-2 cells (Figure $5 \mathrm{~A})$. However, these changes were not observed in $\mathrm{Zpl}$ 3-4 cells. The MLA and PrP(106-126) co-treated group showed increased p62 protein levels compared to those in the $\operatorname{PrP}(106-126)$ treated group (Figure 5B). Consistent with these findings, immunocytochemistry showed that PNU-282987 and PrP(106-126) co-treated cells had increased LC-3 protein levels (green fluorescence) but decreased p62 protein levels (red fluorescence) compared to those in the PrP(106-126) treatment group of ZW 13-2 cells; however, these changes were blocked in Zpl 3-4 cells (Figure 5C). These results suggest that $\alpha 7 \mathrm{nAChR}$ signaling has a neuroprotective effect against $\operatorname{PrP}(106-$ 126)-mediated neurotoxicity by upregulating autophagy and that these protective effect are influenced by PrPC expression in neuron cells.
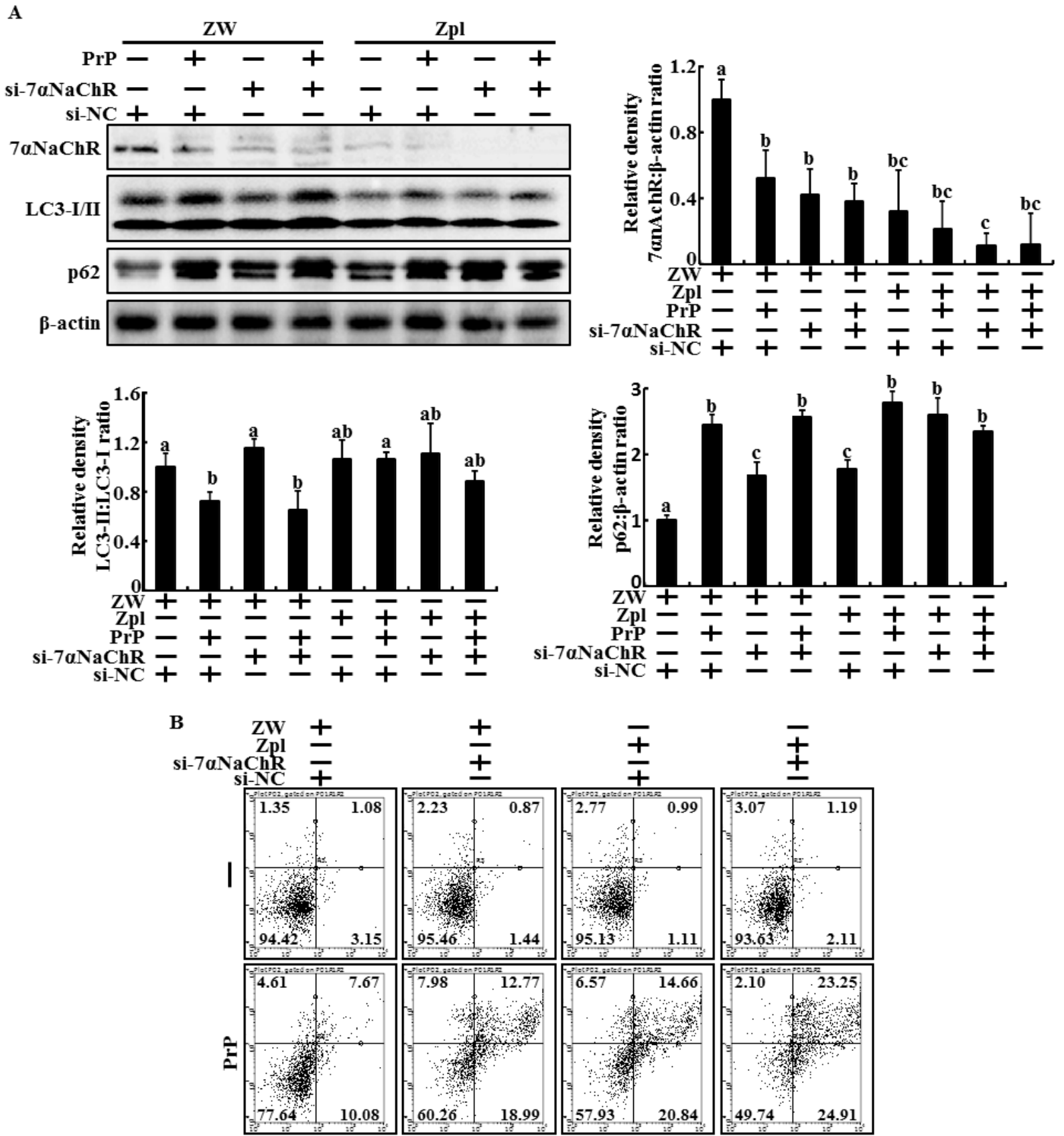

Figure 6: $\alpha$ 7nAchR-mediated autophagic flux regulates by PrPC expression in PrP(106-126)-treated Hippocampal neuron cells. A., $\alpha 7 \mathrm{nAchR}$ siRNA (si- $\alpha 7 \mathrm{nAChR}$ ) or Negative control siRNA (NC) transfected ZW 13-2 and Zpl 3-4 cells were incubated with $50 \mu \mathrm{M}$ PrP. The treated cells were assessed for LC3-I/II, p62, PrPC and $\alpha 7 \mathrm{nAchR}$ production by Western blot analysis. Results were normalized with $\beta$-actin. Expression levels were determined by western blot band quantifications and densitometric values are shown beside the blot. The bar graph indicates the mean \pm S.E.M. $(n=3)$. B., Annexin V assay in ZW 13-2 and Zpl 3-4 cells treated as described in A. 
To verify this hypothesis, we knockdown $\alpha 7 \mathrm{nAChR}$ gene expression using an $\alpha 7 \mathrm{nAChR}$ RNAi oligomer to determine whether PrP(106-126)-induced neurotoxicity was related with PrPC expression or $\alpha 7 \mathrm{nAChR}$-mediated autophagy. A Western blot analysis showed that the $\alpha 7 \mathrm{nAChR}$ RNAi oligomer ( $\alpha 7 \mathrm{nAChR}$ siRNA) treatment inhibited $\alpha 7 \mathrm{nAChR}$ protein levels and increased LC3II and p62 protein levels compared to those in negative control RNAi oligomer-treated ZW 13-2 cells (Figure 6A). However, these changes were not observed in Zpl 3-4 cells (Figure 6A). Additionally, $\operatorname{PrP}(106-126)$-treated cells (ZW 13-2 and Zpl 3-4 cells) showed inhibited autophagic flux signals (Figure 6A). Knockdown of $\alpha 7 \mathrm{nAChR}$ increased the inhibition of autophagic flux in $\operatorname{PrP}(106-126)$-treated ZW 13-2 cells (Figure 6A). However, $\alpha 7 n A C h R$ siRNA did not influence the $\operatorname{PrP}(106-126)$ treatment in $\mathrm{Zpl} \mathrm{3-4}$ cells (Figure 6A). An increase in the number of $\operatorname{PrP}(106-$ 126)-induced Annexin V-positive cells was observed in $\alpha 7 \mathrm{nAChR}$ siRNA transfected ZW 13-2 cells, whereas this change was not observed in $\operatorname{PrP}(106-126)$-treated Zpl 3-4 cells (Figure 6B). Collectively, these data suggest that $\mathrm{PrPC}$ activates autophagic flux by regulating $\alpha 7 \mathrm{nAChR}$ signaling and partially protects neuron cells against prioninduced neurotoxicity.

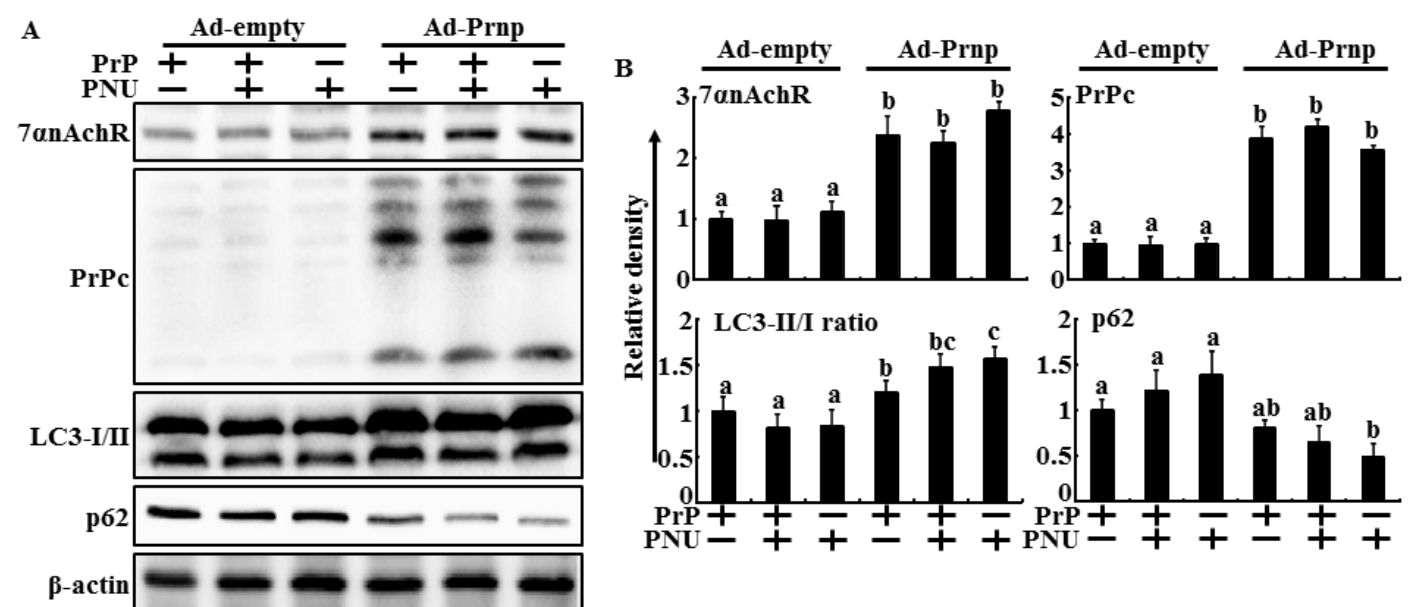

C

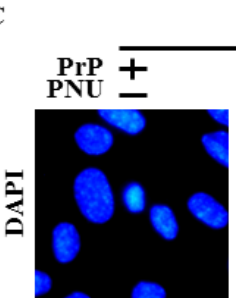

Ad-empty
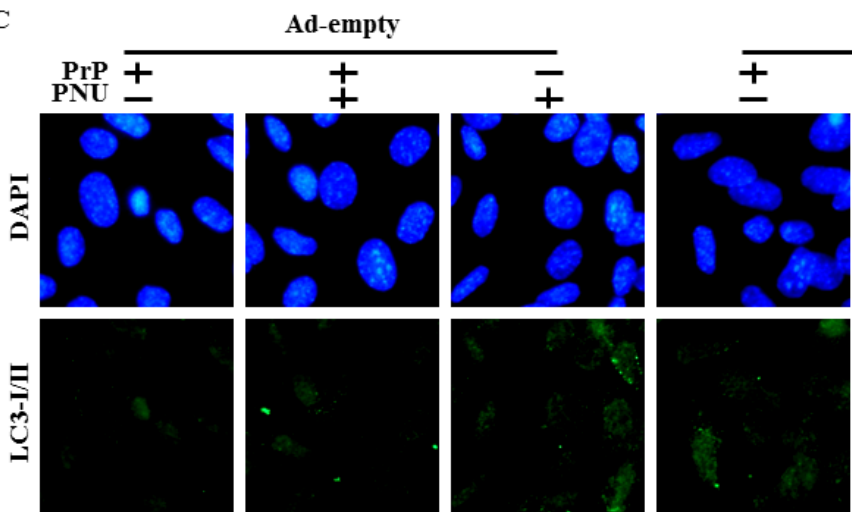

Ad-Prnp
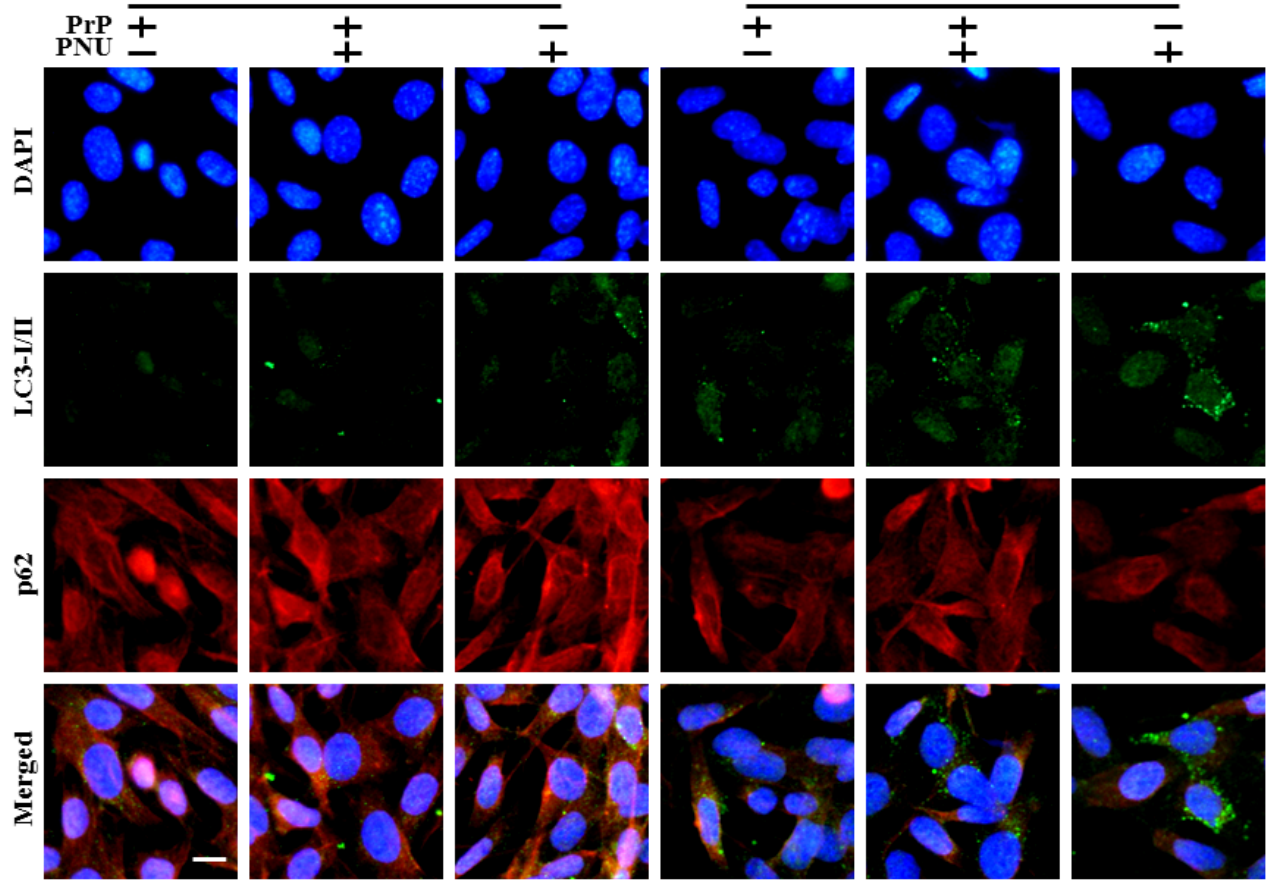

Figure 7: Overexpression of PrPC restored the autophagc effect caused by alpha 7 nAchR in PrPC-deficient neuron

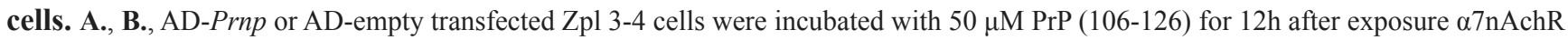
agonist (PNU-282987, $1 \mu \mathrm{M}, 12 \mathrm{~h}$ ) treatment. The treated cells were assessed for $\alpha 7 \mathrm{nAchR}, \mathrm{PrPC}, \mathrm{LC} 3$ and p62 production by Western blot analysis. Results were normalized with $\beta$-actin. Expression levels were determined by western blot band quantifications and densitometric values are shown beside the blot. The bar graph indicates the mean \pm S.E.M. $(n=3)$. C., Representative images of Immunocytochemistry in $\mathrm{Zpl} \mathrm{3-4} \mathrm{cells} \mathrm{treated} \mathrm{as} \mathrm{described} \mathrm{in} \mathrm{A-B.} \mathrm{Scale} \mathrm{bar} \mathrm{denotes} 20 \mu \mathrm{m}$. 
Upregulation of PrPC protects Zpl 3-4 cells against $\operatorname{Pr} P(106-126)$-induced apoptosis by activating $\quad \alpha 7 n A C h R-m e d i a t e d \quad$ autophagic signaling

To verify that PrPC plays a protective role in neuron cells exposed to prion peptide by activating $\alpha 7 \mathrm{nAChR}$ mediated autophagic flux, the recombinant adenovirusexpressing full length Prnp gene (Ad-Prnp) was utilized to overexpress the Prnp gene in $\operatorname{PrP}(106-126)$-treated Zpl 3-4 cells. Transfection of Zpl 3-4 cells with Ad-Prnp resulted in PrPC overexpression compared to that in Adempty transfected cells (Figure 7A and 7B). Ad-Prmp and Ad-empty transfected cells were pre-treated with PNU$282987(1 \mu \mathrm{M}, 12 \mathrm{hr})$ and then exposed to $50 \mu \mathrm{M} \operatorname{PrP}$ (106-126) for $12 \mathrm{hr}$. The result showed that overexpression of $\mathrm{PrPC}$ increased $\alpha 7 \mathrm{nAChR}$ protein expression level and decreased p62 protein level in $\operatorname{PrP}(106-126)$-treated cells. In addition, Ad-Prnp transfected cells had activated autophagic flux signals in response to PNU-282987, whereas Ad-empty transfected cells showed no change in LC3-II/LC3-I ratio or p62 expression level after $\operatorname{PrP}(106-126)$ treatment. Consistent with these results, immunocytochemistry showed that PNU-282987 restored autophagic flux in Ad-Prnp transfected cells (Figure 7C). The Annexin V assay showed that transfection of Ad-Prnp at a multiplicity of infection (MOI) of 500 inhibited PrP (106-126)-induced apoptosis compared to that in cells transfected with Ad-empty at a MOI of 500. PNU-282987 enhanced the protective effect of PrPC expression on PrP (106-126)-mediated neuronal cell death (Figure 8). These data indicate that overexpression of PrPC plays a protective role against prion peptide-induced neuron cell death by upregulating $\alpha 7 \mathrm{nAChR}$-mediated autophagy signaling.

\section{DISCUSSION}

Our results demonstrate that activating $\alpha 7 \mathrm{nAChR}$ prevented prion-mediated neuronal damage by activating autophagic flux and that inducing $\alpha 7 \mathrm{nAChR}$-mediated autophagic flux regulates PrPC expression in neuron cells. A Notably, activation of autophagic flux caused by $\alpha 7 \mathrm{nAChR}$ was related to PrPC expression in neuron cells, which, in turn, conferred neuroprotection.

Some studies have reported that activating $\alpha 7 \mathrm{nAChR}$ regulates cholinergic signaling and may lead to recover cognitive function in Alzheimer's disease models [13, 49, 50]. Nicotine and A-582941, which are $\alpha 7 \mathrm{nAChR}$ agonists, protect neurons from $\mathrm{A} \beta$-induced neuronal damage by upregulating the $\alpha 7 \mathrm{nAChR}$ signaling pathway [50, 51]. ABT-107, which is a $\alpha 7 \mathrm{nAChR}$ agonist, also prevents neurotoxicity induced by 1-dopa-induced
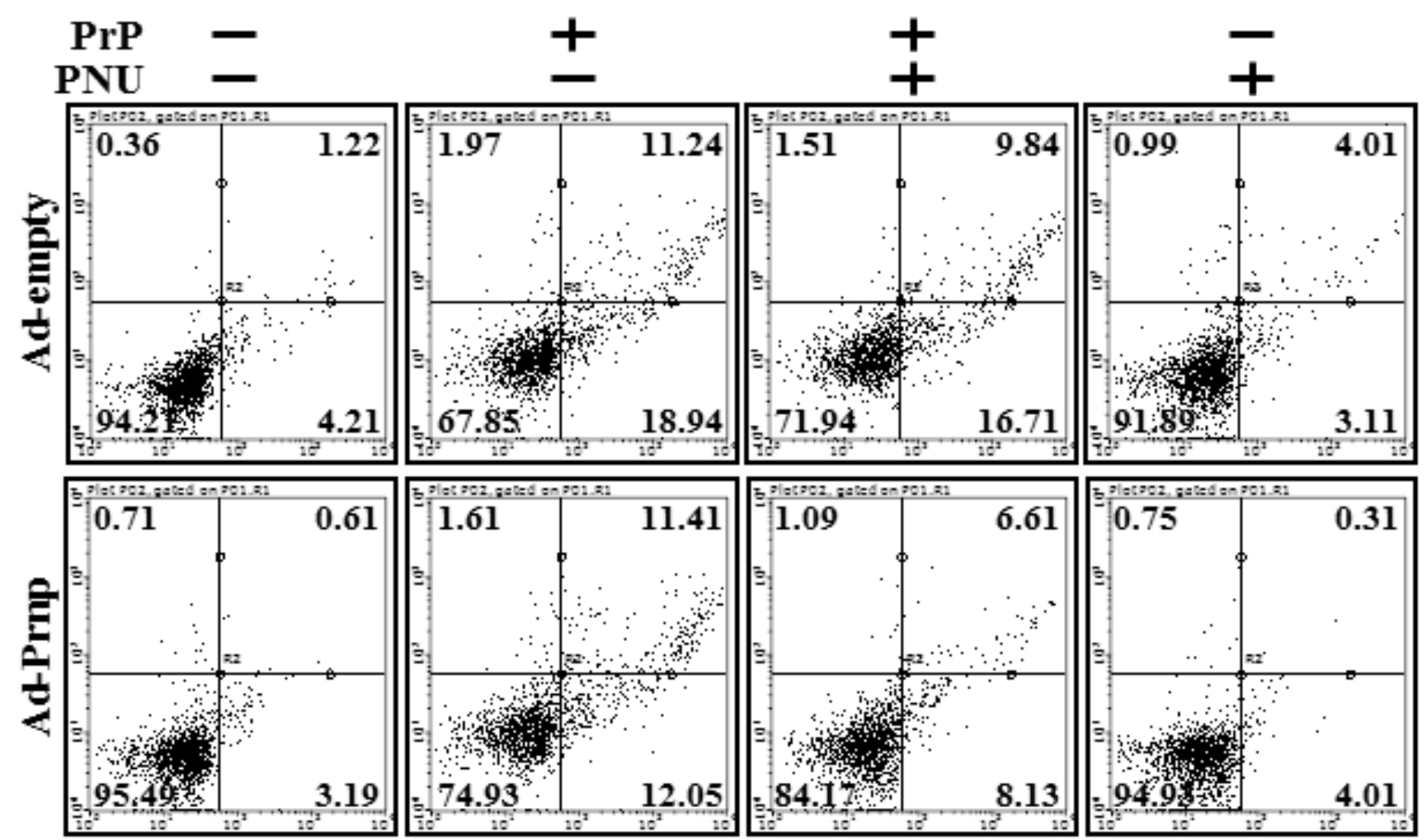

Figure 8: Overexpression of PrPC rescue the protective effect of alpha $7 \mathrm{nAchR}$ in PrPC-deficient neuron cells. ADPrnp or AD-empty transfected Zpl 3-4 cells were incubated with $50 \mu \mathrm{M} \operatorname{PrP}$ (106-126) for 12h after exposure $\alpha 7 \mathrm{nAchR}$ agonist (PNU282987, $1 \mu \mathrm{M}, 12 \mathrm{~h}$ ) treatment. Cell viability was measured by the Annexin V assay. PNU; PNU-282987. 
dyskinesia [52]. Neuronal cholinergic receptors are reduced in patients with Alzheimer's disease; particularly, a7nAChR expression decreases 32\% [53]. Consistent with this finding, we showed here that $\operatorname{PrP}(106-126)$ treated cells had decreased viability (Figure 1A and 1B) and $\alpha 7 \mathrm{nAChR}$ protein expression in primary neuron cells (Figure 1C). In addition, the $\alpha 7 \mathrm{nAChR}$ agonist PNU-282987 protected neuron cells from $\operatorname{PrP}(106-126)$, whereas treatment with the $\alpha 7 \mathrm{nAChR}$ antagonist MLA enhanced PrP(106-126)-mediated neurotoxicity (Figure $1 \mathrm{~A}$ and $1 \mathrm{~B}$ ), although the $\alpha 7 \mathrm{nAChR}$ protein expression did not change (Figure 1C). These data support the hypothesis that regulation of $\alpha 7 \mathrm{nAChR}$ may influence prion-mediated neurotoxicity in neuron cells.

One study reported that $\alpha 7 \mathrm{nAChR}$ activity is regulated by $\mathrm{PrPC}$ expression [9], whereas other studies suggest that PrPC has a protective effect against neuronal damage [48], including prion peptide-mediated neurotoxicity. Also, neuroprotection is associated with autophagic flux signals [43, 44] and the protective effect were inhibited by PrPC depletion in hippocampal cells [23]. One paper showed that PrPC-depleted cells show increased expression of LC3-II, autophagy marker protein levels, and autophagosomes under serum starved conditions [21]. This accumulation of LC3-II is inhibited by transfecting the PrPC gene into PrPC knockout neuron cells [21]. These results indicate that PrPC may downregulate autophagic flux in neuron cells. However, Oh et al. suggested that PrPC knockout neuron cells have impaired autophagic flux caused by oxidative stress, whereas wild-type neuron cells exposed to oxidative stress increase autophagic flux [23]. The main mechanism of misfolded protein-mediated neurotoxicity is oxidative stress [54, 55]. Prion-mediated neurotoxicity is also mainly related with oxidative stress [56-58]. Our results show that the PrPC knockout Zpl 3-4 hippocampal neuron cells increased $\operatorname{PrP}(106-126)$-mediated neurotoxicity compared to that of ZW 13-2 cells. In addition, Zpl 3-4 cells had increased p62 protein levels and LC3-II/LC3-I ratio compared to those of ZW 13-2 cells, but $\operatorname{PrP}(106-$ 126) has no effect in $\mathrm{Zpl} 3-4$ cells (Figure 3A and 3B). Thus, we hypothesize that $\operatorname{PrP}(106-126)$ treatment or depleting the PrPC gene inhibits autophagic flux and that PrPC may prevent prion peptide-mediated neurotoxicity by upregulating autophagic flux in neuron cells.

Autophagy is the main lysosomal catabolic pathway for recycling and degrading old cell organelles [25, 59]. The main function of autophagy is facilitated adaption of cells exposed to microenvironments, including caloric restriction, tumor metastasis, immune reactions, ischemic heart disease, and neurodegeneration [60-62]. One study suggested that activating autophagy may play a neuroprotective role in Alzheimer's disease and is related with $\alpha 7 \mathrm{nAChR}$ signaling [13]. That same study showed that inhibiting $\alpha 7 \mathrm{nAChR}$ signaling or depleting ATG7 gene enhanced $\mathrm{A} \beta$-induced neurotoxicity [13]. Consistent with this finding, our results show that PNU-282987, an $\alpha 7 \mathrm{nAChR}$ agonist, increased LC3-II/LC3-I ratio and decreased p62, a marker of activated autophagic flux, and that $\alpha 7 \mathrm{nAChR}$ antagonist or $\alpha 7 \mathrm{nAChR}$ RNA oligomer treatment inhibited autophagic flux in primary cultured neuron cells (Figs. 1C and 2C). In addition, PNU-282987 protected neuron cells against $\operatorname{PrP}(106-12)$-mediated neurotoxicity and MLA enhanced $\operatorname{PrP}(106-126)$-mediated neurotoxicity (Figure 1A, 1B and 2A). These results also similarly showed in ZW 13-2 cells (Figs. 4). However, the $\alpha 7 \mathrm{nAChR}$-mediated autophagic flux and protective effect disappeared in PrPC knockout Zpl 3-4 cells (Figs. 5 and 6). In addition, we found that depleting PrPC decreased $\alpha 7 \mathrm{nAChR}$ expression (Figure $3 \mathrm{~A}$ and $3 \mathrm{~B}$ ). Thus, we hypothesize that $\operatorname{PrPC}$ is a key factor in the regulation of the $\alpha 7 \mathrm{nAChR}$ pathway and is related with autophagic flux and neuroprotection against prion-mediated neurotoxicity.

PrPC expression demonstrated that PNU282987 did not inhibit prion peptide-mediated neuronal apoptosis and blocked autophagic signals, indicating that activating the $\alpha 7 \mathrm{nAChR}$ pathway has a neuroprotective effect related with PrPC expression. In addition, PrPC overexpression using an adenoviral vector increased PrPC and $\alpha 7 \mathrm{nAChR}$ protein expression levels. Overexpression of PrPC upregulated $\alpha 7 \mathrm{nAChR}$-mediated autophagic flux and activated $\alpha 7 \mathrm{nAChR}$ signaling to prevent $\operatorname{PrP}(106-$ 126)-mediated neurotoxicity in PrPC knockout Zpl 3-4 cells. These observations support the hypothesis that PrPC regulates $\alpha 7 \mathrm{nAChR}$ signals and that activation of $\alpha 7 \mathrm{nAChR}$ signals protects neuronal cells from prionmediated neurotoxicity by regulating the autophagy pathway.

This is the first report demonstrating that $\alpha 7 \mathrm{nAChR}$ signaling is regulated by PrPC expression and that upregulation $\alpha 7 \mathrm{nAChR}$ signaling may be related with autophagy signals that protect against $\operatorname{PrP}(106-126)$ mediated neurotoxicity. These results suggest that upregulation of PrPC and inducers of $\alpha 7 \mathrm{nAChR}$, including nicotine and PNU-282987, may be useful neurotherapeutic strategies for neurodegenerative diseases, including Alzheimer's, Parkinson's, and prion diseases.

\section{MATERIALS AND METHODS}

\section{Materials}

Penicillin-streptomycin solution, trypsinethylene diamine tetra acetic acid (EDTA) solution, Neurobasal Medium (NBM), B27 supplement, Glutamax and fetal bovine serum (FBS) were obtained from Life Technologies/Gibco (Carlsbad, CA, USA). Minimum Essential Medium (MEM) and Dulbecco's Modified Eagle's Medium (DMEM) were purchased from GE Healthcare/HyClone (Logan, UT, USA). 
Methyllycaconitine citrate salt (MLA) and PNU-282987 were purchased from Sigma-Aldrich (St. Louis, MO, USA). The immunoblotting and immunocytochemistry antibodies targeted LC3 and cleaved-caspase-3 (Cell Signaling Technology, Danvers, MA, USA), $\alpha 7 \mathrm{nAchR}$ (Abcam Inc., Cambridge, MA, USA), p62 (Millipore, Temecula, CA, USA) and $\beta$-actin (Sigma-Aldrich).

\section{Primary neuron cell cultures}

$\mathrm{BALB} / \mathrm{c}$ mice brains were isolated from E-15 mice embryos using surgical procedures approved by the Institutional Animal Care and Use Committee of Chonbuk National University. Brain tissues were isolated under sterile conditions, rinsed in HBSS, and minced into small pieces. After dissection, the brain tissues were dissociated in trypsin and plated on poly-D-lysine-coated 24-well plates in MEM, containing 10\% FBS. The medium was replaced with NBM supplemented with B27 and Glutamax after $2 \mathrm{hr}$. All cell cultures were maintained at $37^{\circ} \mathrm{C}$ in $5 \%$ $\mathrm{CO}_{2}$.

\section{Cell culture}

The mouse neuronal cell lines ZW 13-2 and Zpl 3-4, which were established from the hippocampus of ICR $\left(\right.$ Prnp $\left.^{+/+}\right)$and Zürich I Prnp ${ }^{-/-}$mice, respectively, were kindly provided by Professor Yong-Sun Kim (Hallym University, Chuncheon, Kangwon-do, South Korea). The cells were grown in DMEM containing 10\% FBS and gentamycin $(0.1 \mathrm{mg} / \mathrm{ml})$ in a humidified incubator maintained at $37^{\circ} \mathrm{C}$ with $5 \% \mathrm{CO}_{2}$.

\section{PrP (106-126) treatment}

Synthetic PrP (106-126) (sequence, Lys-Thr-AsnMet-Lys-His-Met-Ala-Gly-Ala-Ala-Ala-Ala-Gly-Ala-ValVal-Gly-Gly-Leu-Gly) was synthesized by Peptron (Seoul, Korea). The peptide was dissolved at a concentration of $12.5 \mathrm{mM}$ in sterile DMSO and stored at $-80^{\circ} \mathrm{C}$.

\section{Annexin V assay}

Apoptosis was assessed with the Annexin V assay in detached cells using the Annexin V Assay kit (Santa Cruz Biotechnology, Santa Cruz, CA, USA), according to the manufacturer's protocol. Annexin V was quantified by measuring fluorescence at an excitation wavelength of $488 \mathrm{~nm}$ and an emission wavelength of 525/30 nm using a Guava EasyCyte HT (Millipore)

\section{Terminal deoxynucleotidyl transferase dUTP nick end labeling (TUNEL) assay}

The TUNEL analysis was performed to measure the degree of cellular apoptosis using the APOBrdUTM TUNEL Assay Kit (Invitrogen), following the manufacturer's instructions. Cells were washed with phosphate buffer saline (PBS) and fixed in paraformaldehyde for $15 \mathrm{~min}$. Cells were pre-incubated with $50 \mu \mathrm{L}$ DNA-labeling solution $(10 \mu \mathrm{L}$ TdT reaction buffer, $0.75 \mu \mathrm{L}$ TdT enzyme, and $8 \mu \mathrm{L}$ Br-dUTP) for 1 $\mathrm{hr}$ at $37^{\circ} \mathrm{C}$ and then incubated with $5 \mu \mathrm{L}$ anti-BrdU-FITC antibody for $30 \mathrm{~min}$ at room temperature $\left(20^{\circ} \mathrm{C}\right)$. Finally, the cells were mounted with DakoCytomation fluorescent medium and visualized under a fluorescent microscope (Olympus, Tokyo, Japan). The cells were counterstained with propidium iodide to reveal cell nuclei.

\section{Western blotting}

Cells were lysed in lysis buffer (25 mM HEPES; pH 7.4, $100 \mathrm{mM} \mathrm{NaCl}, 1 \mathrm{mM}$ EDTA, 5 mM $\mathrm{MgCl}_{2}, 0.1$ $\mathrm{mM}$ DTT, and a protease inhibitor mixture). Proteins were electrophoretically resolved by $10-15 \%$ sodium dodecyl sulfate-polyacrylamide gel electrophoresis (SDSPAGE), and immunoblotting was performed as described previously. Equal amounts of lysate protein were resolved by $10-15 \%$ SDS-PAGE and electrophoretically transferred to a nitrocellulose membrane. Immunoreactivity was detected through sequential incubation with horseradish peroxidase-conjugated secondary antibodies and enhanced chemiluminescent reagents. Densitometry of the signal bands was conducted using the Bio-1D densitometer (VilberLourmat, Eberhardzell, Germany). The antibodies used for immunoblotting were $\alpha 7 \mathrm{nAchR}, \mathrm{p}-62$, LC3, $\mathrm{PrPC}$, and $\mathrm{B}$-actin. Images were examined using a FusionFX7 imaging system (Vilber Lourmat).

\section{Immunocytochemistry}

The cells were cultured on glass cover slips, washed with PBS, and fixed in cold acetone for $90 \mathrm{~s}$ at room temperature. They were washed again with PBS, blocked with 5\% FBS in Tris buffered saline with Tween, and incubated with anti-mouse-p-62 (2 $\mu \mathrm{g} / \mathrm{ml})$ monoclonal antibody and anti-rabbit-LC3 (2 $\mu \mathrm{g} / \mathrm{ml})$ polyclonal antibody for $48 \mathrm{hr}$ at room temperature. Unbound antibody was removed by an additional PBS wash, and the cells were incubated with Alexa Fluor 488 anti-rabbit FITC (for the anti-LC3 and anti- $\alpha 7 \mathrm{nAchR}$ antibodies) and Alexa Fluor 546 anti-mouse (for the anti-p62 antibody) IgG antibodies $(4 \mu \mathrm{g} / \mathrm{ml})$ for $2 \mathrm{hr}$ at room temperature. Finally, the cells were mounted using the DakoCytomation fluorescent medium (DAKO, Glostrup, Denmark) and 
visualized under a fluorescence microscope (Olympus).

\section{RNA interference}

The cells were transfected with ATG5 small interfering RNA and $\alpha 7 \mathrm{nAchR}$ small interfering RNA (siRNA; oligoID HSS114104 and oligoID HSS101914; Invitrogen) using Lipofectamine 2000, according to the manufacturer's instructions, respectively. After a 48 $\mathrm{h}$ culture, knockdown efficiency was measured at the protein level by immunoblot. The RNAi Negative Control (Invitrogen) was used as a control.

\section{Adenoviral vectors}

Recombinant adenoviruses expressing the full length PRNP gene (Ad-PRNP) were synthesized by Genenmed (Seoul, Korea). A recombinant adenovirus lacking an expression cassette (Ad-empty) was used as a control. The cells were transfected with Ad-PRNP and Ad$\mathrm{LacZ}$ in MEM media without FBS for $24 \mathrm{hr}$. DMEM with $2 \%$ FBS was added after washing with sterile PBS buffer.

\section{Statistical analysis}

All data are expressed as mean \pm standard deviation and compared using one-way analysis of variance with GraphPad Prism ver. 5.0 software (GraphPad Software, Inc., La Jolla, CA, USA). A $P<0.05$ was considered significant.

\section{ACKNOWLEDGMENTS}

This work was supported by a grant from the National Research Foundation of Korea (NRF), funded by the Korean government (2013R1A2A2A01009614).

\section{CONFLICTS OF INTEREST}

The authors declare no conflicts of interest.

\section{REFERENCES}

1. Thomsen MS, Hansen HH, Timmerman DB and Mikkelsen JD. Cognitive improvement by activation of alpha7 nicotinic acetylcholine receptors: from animal models to human pathophysiology. Curr Pharm Des. 2010; 16(3):323343.

2. Levin E, McClernon FJ and Rezvani A. Nicotinic effects on cognitive function: behavioral characterization, pharmacological specification, and anatomic localization. Psychopharmacology. 2006; 184(3-4):523-539.

3. Tracey KJ. Physiology and immunology of the cholinergic antiinflammatory pathway. J Clin Invest. 2007; 117(2):289296.

4. Li XW and Wang H. Non-neuronal nicotinic alpha 7 receptor, a new endothelial target for revascularization. Life Sci. 2006; 78(16):1863-1870.

5. De Rosa MJ, Esandi Mdel C, Garelli A, Rayes D and Bouzat C. Relationship between alpha 7 nAChR and apoptosis in human lymphocytes. J Neuroimmunol. 2005; 160(1-2):154-161.

6. Jiang Y, Dai A, Zhou Y, Peng G, Hu G, Li B, Sham JS and Ran P. Nicotine elevated intracellular $\mathrm{Ca}(2)(+)$ in rat airway smooth muscle cells via activating and up-regulating alpha7-nicotinic acetylcholine receptor. Cell Physiol Biochem. 2014; 33(2):389-401.

7. Zia S, Ndoye A, Nguyen VT and Grando SA. Nicotine enhances expression of the alpha 3 , alpha 4 , alpha 5 , and alpha 7 nicotinic receptors modulating calcium metabolism and regulating adhesion and motility of respiratory epithelial cells. Res Commun Mol Pathol Pharmacol. 1997; 97(3):243-262.

8. Tsuneki H, Klink R, Lena C, Korn H and Changeux JP. Calcium mobilization elicited by two types of nicotinic acetylcholine receptors in mouse substantia nigra pars compacta. Eur J Neurosci. 2000; 12(7):2475-2485.

9. Beraldo FH, Arantes CP, Santos TG, Queiroz NG, Young K, Rylett RJ, Markus RP, Prado MA and Martins VR. Role of alpha7 nicotinic acetylcholine receptor in calcium signaling induced by prion protein interaction with stressinducible protein 1. J Biol Chem. 2010; 285(47):3654236550 .

10. Di Paolo T, Gregoire L, Feuerbach D, Elbast W, Weiss M and Gomez-Mancilla B. AQW051, a novel and selective nicotinic acetylcholine receptor alpha7 partial agonist, reduces 1-Dopa-induced dyskinesias and extends the duration of 1-Dopa effects in parkinsonian monkeys. Parkinsonism Relat Disord. 2014; 20(11):1119-1123.

11. Liu Y, Zeng X, Hui Y, Zhu C, Wu J, Taylor DH, Ji J, Fan W, Huang $\mathrm{Z}$ and $\mathrm{Hu}$ J. Activation of alpha7 nicotinic acetylcholine receptors protects astrocytes against oxidative stress-induced apoptosis: implications for Parkinson's disease. Neuropharmacology. 2015; 91:87-96.

12. Fan H, Gu R Fau - Wei D, Wei D, Medeiros R, Castello NA, Cheng D, Kitazawa M, Baglietto-Vargas D, Green KN, Esbenshade TA, Bitner RS, Decker MW and LaFerla FM. The alpha7 nAChR selective agonists as drug candidat Fan $\mathrm{H}, \mathrm{Gu} \mathrm{R}$ and Wei D. The alpha7 nAChR selective agonists as drug candidates for Alzheimer's disease. Adv Exp Med Biol. 2015; 827:353-365.

13. Hung SY, Huang WP, Liou HC and Fu WM. Autophagy protects neuron from Abeta-induced cytotoxicity. Autophagy. 2009; 5(4):502-510.

14. Stuckenholz V, Bacher M, Balzer-Geldsetzer M, AlvarezFischer D, Oertel WH, Dodel RC and Noelker C. The alpha7 nAChR agonist PNU-282987 reduces inflammation 
and MPTP-induced nigral dopaminergic cell loss in mice. Journal of Parkinson's disease. 2013; 3(2):161-172.

15. Jonnala RR and Buccafusco JJ. Relationship between the increased cell surface alpha7 nicotinic receptor expression and neuroprotection induced by several nicotinic receptor agonists. Journal of neuroscience research. 2001; 66(4):565572.

16. Thumdee P, Ponsuksili S, Murani E, Nganvongpanit K, Gehrig B, Tesfaye D, Gilles M, Hoelker M, Jennen D, Griese J, Schellander K and Wimmers K. Expression of the prion protein gene (PRNP) and cellular prion protein $(\mathrm{PrPc})$ in cattle and sheep fetuses and maternal tissues during pregnancy. Gene expression. 2007; 13(4-5):283-297.

17. Tanji K, Saeki K, Matsumoto Y, Takeda M, Hirasawa K, Doi K, Matsumoto Y and Onodera T. Analysis of PrPc mRNA by in situ hybridization in brain, placenta, uterus and testis of rats. Intervirology. 1995; 38(6):309-315.

18. Peralta OA and Eyestone WH. Quantitative and qualitative analysis of cellular prion protein $(\operatorname{Pr} P(C))$ expression in bovine somatic tissues. Prion. 2009; 3(3):161-170.

19. Mehrpour $M$ and Codogno P. Prion protein: From physiology to cancer biology. Cancer letters. 2010; 290(1):1-23.

20. Horiuchi M, Yamazaki N, Ikeda T, Ishiguro $\mathrm{N}$ and Shinagawa M. A cellular form of prion protein (PrPC) exists in many non-neuronal tissues of sheep. The Journal of general virology. 1995; 76 ( Pt 10):2583-2587.

21. Oh JM, Shin HY, Park SJ, Kim BH, Choi JK, Choi EK, Carp RI and Kim YS. The involvement of cellular prion protein in the autophagy pathway in neuronal cells. Molecular and cellular neurosciences. 2008; 39(2):238-247.

22. Barbieri G, Palumbo S, Gabrusiewicz K, Azzalin A, Marchesi N, Spedito A, Biggiogera M, Sbalchiero E, Mazzini G, Miracco C, Pirtoli L, Kaminska B and Comincini S. Silencing of cellular prion protein (PrPC) expression by DNA-antisense oligonucleotides induces autophagy-dependent cell death in glioma cells. Autophagy. 2011; 7(8):840-853.

23. Oh JM, Choi EK, Carp RI and Kim YS. Oxidative stress impairs autophagic flux in prion protein-deficient hippocampal cells. Autophagy. 2012; 8(10):1448-1461.

24. Shin HY, Oh JM and Kim YS. The Functional Role of Prion Protein (PrPC) on Autophagy. Pathogens (Basel, Switzerland). 2013; 2(3):436-445.

25. Glick D, Barth $\mathrm{S}$ and Macleod KF. Autophagy: cellular and molecular mechanisms. J Pathol. 2010; 221(1):3-12.

26. Klionsky DJ. Autophagy: from phenomenology to molecular understanding in less than a decade. Nature reviews Molecular cell biology. 2007; 8(11):931-937.

27. Cuervo AM. Autophagy: in sickness and in health. Trends in cell biology. 2004; 14(2):70-77.

28. Cuervo AM. Autophagy: many paths to the same end. Molecular and cellular biochemistry. 2004; 263(1-2):55-72.

29. Johansen T and Lamark T. Selective autophagy mediated by autophagic adapter proteins. Autophagy. 2011; 7(3):279296.

30. Liu S and Li X. Autophagy inhibition enhances sensitivity of endometrial carcinoma cells to paclitaxel. International journal of oncology. 2015; 46(6):2399-2408.

31. Kadowaki M and Karim MR. Cytosolic LC3 ratio as a quantitative index of macroautophagy. Methods in enzymology. 2009; 452:199-213.

32. Karim MR, Kanazawa T, Daigaku Y, Fujimura S, Miotto G and Kadowaki M. Cytosolic LC3 ratio as a sensitive index of macroautophagy in isolated rat hepatocytes and H4-II-E cells. Autophagy. 2007; 3(6):553-560.

33. Mizushima N, Yoshimorim $\mathrm{T}$ and Levine B. Methods in Mammalian Autophagy Research. Cell. 2010; 140(3):313326.

34. Tanida I. Autophagosome formation and molecular mechanism of autophagy. Antioxidants \& redox signaling. 2011; 14(11):2201-2214.

35. Pugsley H, Friend S, Kong R, Vaidyanathan S and Morrissey P. Measuring autophagic flux by assessing LC3, p62 and LAMP1 co-localization using imaging flow cytometry (TECH2P.908). The Journal of Immunology. 2015; 194(1 Supplement):206.218.

36. Kuusisto E, Salminen A and Alafuzoff I. Ubiquitin-binding protein p62 is present in neuronal and glial inclusions in human tauopathies and synucleinopathies. Neuroreport. 2001; 12(10):2085-2090.

37. Kuusisto E, Salminen A and Alafuzoff I. Early accumulation of p62 in neurofibrillary tangles in Alzheimer's disease: possible role in tangle formation. Neuropathology and applied neurobiology. 2002; 28(3):228-237.

38. Nagaoka U, Kim K, Jana NR, Doi H, Maruyama M, Mitsui $\mathrm{K}$, Oyama F and Nukina N. Increased expression of p62 in expanded polyglutamine-expressing cells and its association with polyglutamine inclusions. Journal of neurochemistry. 2004; 91(1):57-68.

39. Liu B, Cheng Y, Liu Q, Bao JK and Yang JM. Autophagic pathways as new targets for cancer drug development. Acta pharmacologica Sinica. 2010; 31(9):1154-1164.

40. Chen $\mathrm{N}$ and Karantza V. Autophagy as a therapeutic target in cancer. Cancer biology \& therapy. 2011; 11(2):157-168.

41. Hung SY, Huang WP, Liou HC and Fu WM. Autophagy protects neuron from Abeta-induced cytotoxicity. Autophagy. 2009; 5(4):502-510.

42. Yang ZJ, Chee CE, Huang S and Sinicrope FA. The role of autophagy in cancer: therapeutic implications. Mol Cancer Ther. 2011; 10(9):1533-1541.

43. Jeong JK, Moon MH, Lee YJ, Seol JW and Park SY. Autophagy induced by the class III histone deacetylase Sirt1 prevents prion peptide neurotoxicity. Neurobiology of aging. 2013; 34(1):146-156.

44. Jeong JK, Moon MH, Lee YJ, Seol JW and Park SY. Melatonin-induced autophagy protects against human prion protein-mediated neurotoxicity. Journal of pineal research. 
2012; 53(2):138-146.

45. Lee IH, Cao L, Mostoslavsky R, Lombard DB, Liu J, Bruns NE, Tsokos M, Alt FW and Finkel T. A role for the NADdependent deacetylase Sirt1 in the regulation of autophagy. Proceedings of the National Academy of Sciences of the United States of America. 2008; 105(9):3374-3379.

46. Huang R, Xu Y, Wan W, Shou X, Qian J, You Z, Liu B, Chang C, Zhou T, Lippincott-Schwartz J and Liu W. Deacetylation of Nuclear LC3 Drives Autophagy Initiation under Starvation. Molecular cell. 2015; 57(3):456-466.

47. Hariharan N, Maejima Y, Nakae J, Paik J, Depinho RA and Sadoshima J. Deacetylation of FoxO by Sirt1 Plays an Essential Role in Mediating Starvation-Induced Autophagy in Cardiac Myocytes. Circulation research. 2010; 107(12):1470-1482.

48. Jeong JK, Seo JS, Moon MH, Lee YJ, Seol JW and Park SY. Hypoxia-inducible factor-1 alpha regulates prion protein expression to protect against neuron cell damage. Neurobiology of aging. 2012; 33(5):1006.e1001-1010.

49. Thomsen MS, Hansen HH, Timmerman DB and Mikkelsen JD. Cognitive improvement by activation of alpha7 nicotinic acetylcholine receptors: from animal models to human pathophysiology. Current pharmaceutical design. 2010; 16(3):323-343.

50. Srivareerat M, Tran TT, Salim S, Aleisa AM and Alkadhi KA. Chronic nicotine restores normal Abeta levels and prevents short-term memory and E-LTP impairment in Abeta rat model of Alzheimer's disease. Neurobiology of aging. 2011; 32(5):834-844.

51. Toyohara J and Hashimoto K. alpha7 Nicotinic Receptor Agonists: Potential Therapeutic Drugs for Treatment of Cognitive Impairments in Schizophrenia and Alzheimer's Disease. The open medicinal chemistry journal. 2010; 4:3756.

52. Zhang D, McGregor M, Decker MW and Quik M. The alpha7 nicotinic receptor agonist ABT-107 decreases L-Dopa-induced dyskinesias in parkinsonian monkeys. The Journal of pharmacology and experimental therapeutics. 2014; 351(1):25-32.

53. Wevers A, Monteggia L, Nowacki S, Bloch W, Schutz U, Lindstrom J, Pereira EF, Eisenberg H, Giacobini E, de Vos RA, Steur EN, Maelicke A, Albuquerque EX and Schroder H. Expression of nicotinic acetylcholine receptor subunits in the cerebral cortex in Alzheimer's disease: histotopographical correlation with amyloid plaques and hyperphosphorylated-tau protein. The European journal of neuroscience. 1999; 11(7):2551-2565.

54. Ryan BJ, Hoek S, Fon EA and Wade-Martins R. Mitochondrial dysfunction and mitophagy in Parkinson's: from familial to sporadic disease. Trends Biochem Sci. 2015; 40(4):200-210.

55. Jaronen M, Goldsteins G and Koistinaho J. ER stress and unfolded protein response in amyotrophic lateral sclerosis-a controversial role of protein disulphide isomerase. Frontiers in cellular neuroscience. 2014; 8:402.

56. Sorce S, Nuvolone M, Keller A, Falsig J, Varol A, Schwarz $\mathrm{P}$, Bieri M, Budka H and Aguzzi A. The role of the NADPH oxidase NOX2 in prion pathogenesis. PLoS pathogens. 2014; 10(12):e1004531.

57. O'Donovan CN, Tobin D and Cotter TG. Prion protein fragment PrP-(106-126) induces apoptosis via mitochondrial disruption in human neuronal SH-SY5Y cells. The Journal of biological chemistry. 2001; 276(47):43516-43523.

58. Sakudo A and Ikuta K. Prion protein functions and dysfunction in prion diseases. Curr Med Chem. 2009; 16(3):380-389.

59. Mortimore GE, Miotto G, Venerando R and Kadowaki M. Autophagy. Sub-cellular biochemistry. 1996; 27:93-135.

60. Maes H, Rubio N, Garg AD and Agostinis P. Autophagy: shaping the tumor microenvironment and therapeutic response. Trends in molecular medicine. 2013; 19(7):428446.

61. Martins JD, Liberal J, Silva A, Ferreira I, Neves BM and Cruz MT. Autophagy and inflammasome interplay. DNA Cell Biol. 2015; 34(4):274-281.

62. Cheng H, Fan X, Lawson WE, Paueksakon P and Harris RC. Telomerase deficiency delays renal recovery in mice after ischemia-reperfusion injury by impairing autophagy. Kidney Int. 2015; 88(1):85-94. 